Economia e Sociedade, Campinas, Unicamp. IE. http://dx.doi.org/10.1590/1982-3533.2021v30nespart02

\title{
Soberania, industrialização e integração nacional: Wilson Cano e os mosaicos do desenvolvimento brasileiro *
}

\author{
Danilo Severian ** \\ Antonio Corrêa de Lacerda ${ }^{* * *, * * * *}$
}

\section{Resumo}

A obra de Wilson Cano perpassa diferentes aspectos do desenvolvimento econômico, tendo como centralidade a preocupação com a soberania nacional. $\mathrm{O}$ artigo traz uma leitura da produção intelectual de Cano destacando sua abordagem original sobre os aspectos regionais da industrialização brasileira e a importância que o complexo capitalista cafeeiro exerceu neste processo. Destaca e qualifica, ainda, os períodos de concentração e desconcentração da atividade industrial no território brasileiro em relação ao Centro-Sul, sobretudo quanto ao estado de São Paulo, e os efeitos deletérios que a reorientação do papel do Estado e a hegemonia das políticas de corte neoliberal exerceram sobre a dinâmica regional e a estrutura produtiva do país. Os sentidos que as políticas de corte regional assumem contemporaneamente também são tratados à luz do debate proposto por Wilson Cano, bem como as possibilidades de retomada do aparelho industrial no Brasil.

Palavras-chave: Cano, Wilson, 1937-2020, Desigualdades regionais no Brasil, Indústria e território, Desindustrialização, Políticas de desenvolvimento regional.

\begin{abstract}
Sovereignty, industrialization and national integration: Wilson Cano and the Brazilian development mosaics

The work of Wilson Cano analyzes different aspects of economic development, the central theme of which is national sovereignty. This paper provides an interpretation of Cano's intellectual production, highlighting his original approach to regional aspects of Brazilian industrialization and the importance of the capitalist complex of coffee in this process. It highlights and qualifies the periods of concentration and deconcentration of Brazilian industrial activities in relation to the Central-South region, especially as regards the state of São Paulo, and the deleterious effects that the reorientation of the role of the State and the hegemony of reducing neoliberal policies have on regional dynamics and the country's production structure. The current regional policies are also studied in light of the debate proposed by Wilson Cano, as well as the possibilities to recapture the industrial core in Brazil.
\end{abstract}

Keywords: Cano, Wilson, 1937-2020, Regional inequalities in Brazil, Industry and territory, Deindustrialization, Regional development policies.

JEL R12, R58, L52, L60.

\section{Introdução}

O artigo se propõe a uma análise da obra de Wilson Cano, especialmente no que se refere às questões da soberania, industrialização e integração regional. Uma preocupação central que permeia a produção intelectual de Cano é o da soberania nacional, embora nem sempre tratada de maneira

\footnotetext{
${ }^{*}$ Artigo recebido em 31 de março de 2021e aprovado em 29 de julho de 2021.

** Pesquisador associado do Instituto de Pesquisa Econômica Aplicada (Ipea), Brasília, DF, Brasil. E-mail: danilo_severian@ @otmail.com. ORCID: https://orcid.org/0000-0002-9557-516X.

*** Professor-doutor do Programa de Pós-Graduação em Economia Política da Pontifícia Universidade Católica de São Paulo (PUC-SP). São Paulo, SP, Brasil. E-mail: aclacerda@ @aclacerda.com. ORCID: https://orcid.org/0000-0001-8852-4172.

**** Atual presidente do Conselho Federal de Economia (Cofecon), Brasília, DF, Brasil.
} 
direta. Seus trabalhos se endereçam continuamente ao tema, seja pela perspectiva da necessária industrialização enquanto estratégia para tal, seja pela análise dos conflitos distributivos que envolvem internamente o território e a espacialização da atividade produtiva, especialmente aquelas concernentes ao meio urbano e que desnudam as profundas desigualdades sociais do país.

Deste modo, Wilson Cano continua uma tradição da Economia Política crítica, que busca dissecar do particular os elementos que dão sentido e conformação ao todo, debruçando-se sobre a relação dialética entre os fenômenos econômicos e sociais e suas interações mutuamente e simultaneamente transformadoras. Para isso, recorre à história e às peculiaridades que singularizam seu objeto de pesquisa em dado contexto: as cidades, a industrialização, a estrutura fundiária rural e a agricultura itinerante, a formação regional do Brasil, a reflexão sobre a América Latina e as relações de poder no mundo capitalista entre o centro e a periferia.

Nesse sentido, Cano não pode ser reduzido às compartimentações das disciplinas econômicas: referência no estudo da questão regional e urbana, também o foi em relação aos caminhos e descaminhos da indústria no Brasil e das políticas de desenvolvimento, além de um crítico ferrenho do neoliberalismo a que vem se submetendo a política econômica latino-americana desde 1980. Em sua obra, o local e o global se conectam e são indissociáveis para a compreensão da dinâmica econômica nacional e do grau de dominação a que se sujeitam as economias não-centrais na arquitetura de poder global. Isso quer dizer que é preciso conhecer as sobredeterminações externas para se perceber as estratégias possíveis de afirmação nacional. Essa articulação entre o local e o global quebram de maneira contundente as concepções "localistas" e do "small is beautiful", tão distantes da realidade da periferia, quiçá do mundo real, ao problematizar os receituários de políticas públicas impostas a partir da retomada da hegemonia americana ao final dos 1970.

Seu rigor histórico é inseparável de seu compromisso metodológico quando trabalhava diretamente com os dados. Esse rigor legou a gerações de alunos e pesquisadores um compromisso com o tratamento responsável da informação primária e a busca contínua por indicadores que traduzissem de maneira assertiva os movimentos do real, sem perder o senso crítico e a desconfiança sadia em relação aos números e metodologias das pesquisas disponíveis - prova disso é sua reiterada crítica à descontinuação dos Censos Industriais pelo IBGE.

Não se pode deixar de pontuar que os traços da personalidade intelectual de Wilson Cano estão profundamente vinculados à sua formação cepalina e à influência que Celso Furtado exerceu sobre ele; talvez resida aí sua preocupação permanente com a questão da soberania nacional, da industrialização tardia e periférica, com as feições regionais impressas por essa industrialização e o modo de inserção que o Brasil e demais países industrializados da América Latina assumiram na divisão internacional do trabalho durante o século XX. Todos são temas tratados por Furado e que orbitam nas preocupações da escola histórico-estruturalista. Como não poderia deixar de ser, Cano era um intelectual com posição política clara e militante, o que nunca significou concessões partidárias à suas convicções ou reducionismo a posturas panfletárias.

O presente artigo pretende abordar aspectos selecionados da obra do Professor e refletir sobre alguns temas que são importantes na coesão de seu pensamento e produção intelectual. Na primeira seção, retoma-se os aspectos marcantes de sua contribuição para a questão regional brasileira, lidos sob o interesse da gênese da industrialização no país. Na segunda seção, discorre-se sobre o processo 
de industrialização entre 1930 e 1980 e os períodos de concentração e desconcentração da atividade manufatureira no território nacional, qualificando-os. Na terceira seção, busca-se problematizar em como as políticas de recorte territorial têm se articulado às políticas macroeconômicas no período recente. Na quarta seção, discute-se os aspectos que tem tirado o Brasil do caminho do desenvolvimento com equidade social, com a debilitação de sua indústria e consequentemente de sua soberania, sem deixar de apontar perspectivas para a superação dos desafios impostos ao país. Por fim, tecem-se as conclusões.

\section{Raízes da indústria e da "Questão Regional” na obra de Wilson Cano}

A transversalidade dos temas tratados por Wilson Cano tem como denominador comum a aplicação do método histórico-estrutural, ferramenta que o possibilitou abordar um amplo leque de fenômenos em perspectiva não só temporalmente ampliada como bem encadeada. Sem abdicar de uma coesão lógica em assuntos aparentemente distantes, Wilson Cano buscou na interpretação radical dos processos históricos, econômicos e políticos as elucidações para as questões que tomavam sua atenção.

Não por outro motivo sua tese de doutoramento, "Raízes da Concentração Industrial em São Paulo" (Cano, 1977), foi o resultado de um passo atrás: o que seria uma antessala ao objeto principal de pesquisa - os aspectos regionais da industrialização brasileira pós-1930 - converteu-se no próprio objeto de investigação. O autor compreendeu que não poderia partir das políticas sistemáticas de promoção do desenvolvimento industrial iniciadas pela "Era Vargas", inauguradas sob a sombra da crise de 1929, como se a incipiente indústria previamente instalada fosse parte de um processo historicamente menor ou dado, o que sugeriria uma desconexão entre o início de uma estratégia política industrializante, a região preferencial que captou parte significativa desse desenvolvimento e o passado da indústria no país.

Era preciso, portanto, analisar a fundo as condições particulares que fizeram do estado de São Paulo o principal lócus da indústria nacional, a despeito das demais regiões, algumas chegando a regredir industrialmente após 1930. Isso exigiu uma cuidadosa leitura do papel da agricultura mercantil no estado e das relações sociais ali estabelecidas durante o século XIX e início do XX. Assim, Cano trouxe uma contribuição autêntica e original sobre o papel do complexo econômico cafeeiro na constituição do mercado de consumo em São Paulo ${ }^{1}$, possibilitado por fatores como: a resolução pioneira à questão da mão de obra na segunda metade do século XIX, substituindo o trabalho escravizado pelo assalariado; pelo desenvolvimento diversificado de uma agricultura comercial produtora de alimentos e voltada ao mercado urbano; e por condições técnicas e ambientais que possibilitaram uma elevada ampliação do excedente sob controle da burguesia paulista, tanto pela ocupação de terras voltadas à cafeicultura quanto pela diversificação dos negócios.

A incorporação do imigrante europeu às lavouras via assalariamento, após formas embrionárias e pré-capitalistas de produção, como a "parceria" e o "colonato", propiciaram a formação e o progressivo alargamento do mercado regional, o que estava obstado em outras partes do país, como no Nordeste, onde as relações pré-capitalistas de exploração da força de trabalho

(1) Isto é, da progressiva predominância de relações de troca pautadas pela circulação monetária. 
persistiam na forma do cambão, do barracão, etc. - expressões de opressão lamentavelmente ainda presentes no meio rural do país. Portanto, foi a capacidade do complexo cafeeiro paulista em assimilar as formas capitalistas de produção que permitiu a reprodução ampliada de seu capital e uma ampla vantagem dessa região em relação às demais na dinamização do processo de acumulação.

O fato de a produção cafeeira ter se forjado enquanto um complexo capitalista significou a instalação de uma cadeia interdependente, relativamente ampla e diversificada da produção sob o domínio de brasileiros, que se articulava desde o financiamento até o principal ponto final da circulação mercantil do país: o porto de Santos. Isso implica dizer que São Paulo caracterizou-se por um arranjo produtivo que terminava por estender a divisão social do trabalho, complexificando as relações sociais de produção, reprodução e circulação, em contraponto ao perfil de enclave que as economias regionais estagnadas ou decadentes sustentavam enquanto remanescentes dos grandes ciclos mercantis anteriores, preservando unidades produtivas semi-autárquicas e com interações nãocapitalistas.

Esta interdependência econômica que demarcava o complexo cafeeiro ganhava expressão territorial com a progressiva ocupação do interior do estado na busca por terras favoráveis à lavoura, marchando no sentido do oeste paulista. O exaurimento do solo e envelhecimento dos cafezais no Vale do Paraíba, tanto pelo lado fluminense quanto paulista, somado à predominância do emprego da força de trabalho escravizada na região, atuavam na redução da produtividade e elevação dos custos, sobretudo ao final do século XIX, quando se rareava a disponibilidade de cativos. Esse movimento de ocupação bem-sucedido no oeste, dada a qualidade do solo e disponibilidade de terras, abriu pelo território ferrovias que auxiliaram na criação e integração da rede urbana estadual, constituindo uma infraestrutura importante às atividades industriais que viriam a florescer. A própria indústria auxiliar ao capital mercantil-exportador, como as de sacaria de juta na região de Campinas, importante entroncamento para o escoamento da produção rumo ao porto de Santos, é exemplar nesse sentido, descrevendo também o perfil pouco sofisticado que essa manufatura pré-1930 assumia. O núcleo econômico, ou a atividade que dava sentido econômico à organização capitalista da produção era o complexo cafeeiro, e mesmo as indústrias de bens de consumo leves, destacadamente a têxtil, dependiam em alguma medida do desempenho do setor dominante. De todo modo, eram indústrias cerceadas pela estreita dimensão do mercado interno, visto o baixíssimo nível dos salários e a elevada propensão a importar das elites.

Cano demonstra que não necessariamente havia movimentos síncronos entre o desempenho da cafeicultura e o da indústria no contexto pré-1930. Houve momentos em que a demanda externa respondia favoravelmente ao café e a indústria se animava internamente, e aqueles onde o enfraquecimento do setor externo debilitava tanto o complexo cafeeiro quanto a indústria, sobretudo pela restrição trazida à capacidade de importar em um cenário de elevada dependência externa de alimentos $^{2}$ e bens de produção industrial (intermediários e de capital).

Se, por um lado, uma queda de lucratividade na atividade cafeeira liberava capitais para buscar valorização no setor industrial, as desvalorizações cambiais voltadas a defender o preço do café em momentos de baixa repercutiam em efeitos refreadores à indústria, pela já mencionada

(2) A atenuação dessa dependência alimentar só ocorreria a partir do início do século XX, com o desenvolvimento da agricultura comercial de gêneros alimentícios. 
restrição à capacidade de importar. Contudo, também houve certos momentos em que o café ia bem e a indústria mal, e vice-versa. O fundamental, para além da observação conjuntural das taxas de crescimento e queda, é apreender que havia uma relação hierárquica entre o capital mercantilexportador ligado ao café e o capital industrial, sendo, em primeira e última instância, os estímulos externos que determinavam o vigor da economia brasileira pré-1930.

Nesse contexto, Wilson Cano chama a atenção, em linha com João Manuel Cardoso de Mello (1991), que a existência de indústrias no país não significa ser industrializado ou estar em processo de industrialização. Isso implica centralidade do padrão de acumulação comandado pela manufatura, numa dinâmica assentada na realização e inversão interna de grande parte do excedente do setor, que amplia e diversifica suas condições de oferta. Neste quadro, portanto, a indústria exerce papel central na organização socioeconômica do país. Assim, a despeito de haver indústrias no Brasil antes de 1930 e de São Paulo já deter importante participação no setor, não se observava um processo de industrialização no período pré-1930, pois não se tratava de um padrão de acumulação comandado pela manufatura. Pelo contrário, esta era um corolário do complexo cafeeiro. Foi apenas com as políticas de promoção do processo de substituição de importações na década de 1930, com forte intervenção estatal, que a orientação do aparelho produtivo passou a centrar-se na manufatura e voltar-se para os determinantes internos da acumulação.

A ênfase que Wilson Cano dava ao período Vargas como ponto de virada estrutural do país, e à importância que o complexo cafeicultor paulista e a crise de 1929 exerceram para a gestação de uma nova consciência e configuração das relações capitalistas de produção no sentido da industrialização, pode ser atestada pelo reiterado número de vezes em que o autor se dedica ao resgate do contexto histórico do período (Cano, 2007; 2012...). Não é um exercício menor ou demonstração pretenciosa de erudição soft science, senão o emprego de um método analítico que dimensiona as relações capitalistas de produção dentro dos determinantes históricos particulares em que estas se forjaram. A inadequação teórica dos arsenais manualizados, inclusive aqueles da regional science, se desvela pelo vício neoclássico de negação da história e da suposta ergodicidade das relações econômicas. Seguindo a tradição da economia política crítica, Wilson Cano rejeita modelos transplantados e empreende um esforço genuíno e radical, no sentido da busca pelo essencial, ao interpretar os processos históricos munido de ferramental teórico que escrutina as origens, a evolução e as singularidades da industrialização na periferia capitalista, apoiando-se na escavação zelosa de dados estatísticos que o suportam no entendimento de uma época e dos fenômenos nela gestados.

É evidente que captar os elementos que conduziram às transformações estruturais da economia brasileira a partir da década de 1930 passa pela consideração dos interesses particulares de uma classe industrial ascendente, inclusive na dimensão política, e que passou a ver seus objetivos imbricados aos de setores imiscuídos nos destinos políticos do país, particularmente com os segmentos militares.

Essa simbiose foi bem-sucedida nas circunstâncias históricas da "Revolução de 1930", promovendo a integração do território e a consequente diluição dos "arquipélagos regionais", induzindo conflitos com oligarquias ancestralmente consolidadas regionalmente. Impunha-se, nesse processo, os interesses de uma burguesia industrial gestada no complexo cafeeiro e voltada à realização do valor segundo a plenitude do modo capitalista de produção de mercadorias - 
destacadamente convertendo o trabalho numa delas. Sua capacidade de disputar novos mercados de maneira competitiva significou o desmantelamento de indústrias que contavam com os mecanismos de proteção de seus "arquipélagos".

Em termos concretos, a reconfiguração da estrutura de poder e de acumulação capitalista a partir de 1930 pôs fim às tarifas interestaduais, que preservavam o poder das elites locais ao impedir a concorrência com outras "regiões", instituindo em seu lugar um imposto nacional sobre o consumo. Adotou-se políticas cambiais que viabilizaram as importações industriais, permitindo a incorporação do progresso técnico e os decorrentes ganhos de produtividade. A integração dos mercados ocorreu pelo mecanismo mais rápido e menos custoso: o modal rodoviário, que pôde expandir-se mais facilmente pelo imenso território. A autonomia alfandegária por parte das unidades da federação sobre o mercado externo foi extinta, cabendo a centralização da competência em mãos da União, que elevou significativamente os preços relativos das importações a fim de favorecer a indústria nascente, concretizando dessa maneira o processo de substituição de importações. Dessa maneira, entre 1933 e 1939, a indústria nacional cresceu a uma taxa de 11,2\%, sendo São Paulo o centro dinâmico desse movimento, crescendo 14\% (Cano, 1985).

Fundamentalmente, o período inaugurado pela ascensão de Getúlio Vargas significou a centralização político-administrativa do país pela União e o enfraquecimento da autonomia dos entes federados. A contrapartida às velhas oligarquias rurais, que tinham na "autonomia regional" a expressão de seu poder local, foi a manutenção de um regime fundiário que, ao obstar o acesso à terra, preservava seu domínio político-econômico. A manutenção desse "pacto de elites" produziu pressões que se tornaram evidentemente insuportáveis nos anos 1950/60, pois de um lado conduzia a uma explosão demográfica e de pobreza extensiva nas grandes cidades do Centro-Sul do país, ao mesmo tempo em que agravava os conflitos sociais no campo.

A Superintendência do Desenvolvimento do Nordeste (Sudene) surge em meio ao contexto de exacerbação dos problemas urbanos e agravamento dos conflitos rurais, ao mesmo tempo em que o debate sobre a "questão regional", ou o problema dos "desequilíbrios regionais", são paulatinamente incorporados à teoria do subdesenvolvimento. Autores como François Perroux (1967), Gunnar Myrdal (1965) e Albert Hirschman (1961) são fundamentais nesse momento para a elaboração de uma leitura que situava as especificidades da periferia capitalista no processo de crescimento econômico, nunca "equilibrado": o crescimento, pelo contrário, pressupõe a agudização dos desequilíbrios, e seus resultados, se não corretamente administrados, fundem o problema social ao problema regional, ou, de outra forma, reproduzem a desigual distribuição da renda numa perspectiva das regiões.

Essa literatura penetra de maneira importante na Cepal, sendo marcante para Celso Furtado e claramente referenciada no diagnóstico elaborado por ele no Grupo de Trabalho para o Desenvolvimento do Nordeste (GTDN, 1959), que lançaria as bases para a criação da Sudene, em 1959. Parte-se da constatação de que o processo de industrialização nos países subdesenvolvidos tende a ocorrer de forma concentrada no território, dadas as limitações de tamanho do mercado, a baixa capacidade de poupança e a necessidade de aproveitamento das externalidades positivas criadas em determinadas regiões do país, por motivos pregressos e variados. Tendo como base essa leitura, 
era preciso, segundo o GTDN, a promoção da reversão deste quadro através da planificação, promovendo uma "industrialização autônoma" da região Nordeste.

\section{Industrialização retardatária e acelerada: da fase restringida à pesada e suas dinâmicas regionais}

O modelo levado a cabo entre 1933 e 1955 foi caracterizado como de "industrialização restringida" por M. C. Tavares (2000), conceito também adotado por J. M. C. Mello (1991) e por Wilson Cano (1985). Ele circunscreve um primeiro período em que o processo de industrialização se gesta num ambiente de restrições técnicas e financeiras que refreiam a consolidação de um setor produtor de bens de capital que dê condições ao conjunto do aparelho produtivo de se antecipar à demanda e suportar um crescimento econômico mais vigoroso, gerando novas demandas industriais e induzindo a ampliação e sofisticação do terciário.

Portanto, trata-se de uma indústria voltada aos bens-salários que se reproduz pela extensão horizontal da produção, predominantemente replicando os padrões tecnológicos de produção precedentes. Nesse modelo, é de se esperar que aquelas regiões com mercados melhor estruturados obtenham vantagens tanto na esfera da produção quanto da circulação, visto que podem intensificar e expandir seu fluxo econômico. O produto real da indústria brasileira mais que triplicou entre 1919 e 1939, tendo o produto da periferia industrial nacional (Brasil - São Paulo) triplicado. Já o estado de São Paulo quadruplicou seu parque industrial no período e, uma década depois, cresceu duas vezes e meia mais, enquanto a periferia nacional era industrialmente quase o dobro do que fora em 1939.

Esses dados trazidos por Cano permitem respaldar sua negação acerca da existência de um "imperialismo paulista sanguessuga", visto que, apesar da elevação da concentração industrial em São Paulo devido aos diferenciais de crescimento e de seu protagonismo a nível nacional, o produto industrial do país como um todo crescia de maneira acelerada, saltando de uma taxa média de 4,4\% entre 1920 a 1928 para 7,8\% entre 1930 e 1949, enquanto o estado de São Paulo cresceu, respectivamente, $6,6 \%$ e $9,7 \%$ e a periferia nacional, $3,3 \%$ e $6,2 \%$.

A mudança no padrão de acumulação para a "industrialização pesada" viria a ocorrer em meados dos anos 1950, apoiada pelo estrangulamento externo do pós-guerra, o que implicava em importantes restrições na capacidade de suprimento da estrutura industrial interna e estímulos à produção doméstica; e pelo Programa de Metas, que viria a alterar o patamar das taxas de crescimento industrial pela captação externa de capitais de risco e consolidação dos setores de bens duráveis e de capital. Essa incursão de capitais no país resolvia parcialmente os problemas cambiais, ao mesmo tempo em que estabelecia os segmentos mais sofisticados e intensivos em capital com protagonismo das empresas oligopolistas transnacionais, que se instalaram com capacidade ociosa planejada, investimentos de grande porte e densidade de capital, dos quais o setor automobilístico é o mais simbólico. Apoiado pelas empresas Estatais nas indústrias de base (energia, metalurgia, petroquímica, etc.) e pelas políticas de subsídio às remessas de lucros (instrução n. 113 da Sumoc), o departamento produtor de bens de capital e de consumo durável terminou por reforçar a hegemonia da manufatura paulista no mercado nacional, sendo o principal estado receptor dos investimentos, dadas as externalidades positivas previamente constituídas no contexto do ciclo cafeeiro. 
Com a maturação, nos anos 1970, dos grandes investimentos empreendidos na década de 1960, passou-se a observar um maior crescimento da periferia nacional em relação a São Paulo. Na década de 1970, a taxa de crescimento do país foi de 10,2\%, enquanto São Paulo cresceu 8,1\% (Cano, 2007), com a maioria dos Estados apresentando taxas mais elevadas do que este, à exceção do Rio de Janeiro e Pernambuco. Quanto à indústria, São Paulo detinha 58\% da produção nacional do setor no ano de 1970, participação que na década seguinte caiu para 53\%. Embora tenha crescido a altas taxas em termos absolutos, essa perda relativa do estado está associada à queda na participação da Região Metropolitana de São Paulo, que respondia por 44\% do produto industrial nacional em 1970, reduzindo-se para 33\% em 1980 (Diniz, 1993).

Cabe notar que houve um movimento de ocupação da indústria no próprio interior do Estado de São Paulo durante os anos de 1970, derivado das políticas de descentralização tanto do governo estadual quanto federal, ao viabilizarem um importante conjunto de obras em infraestrutura (com destaque à rodoviária) e de pesquisa, com a capilarização de universidades e centros de pesquisa no interior do Estado (Diniz, 2002). Esses fatores são fortes indutores de aglomerações industriais, especialmente em setores mais intensivos em pesquisa e tecnologia. Merecem destaque os municípios de Campinas, Sorocaba e São José dos Campos, que reúnem universidades, institutos e centros de pesquisas importantes a nível nacional, indústrias tecnologicamente sofisticadas e boa integração rodoviária. Como resultado, se em 1970 a RMSP respondia por $75 \%$ da produção industrial do Estado, essa participação caiu para 63\% em 1980. Ao mesmo tempo em que a RMSP perdia posição relativa frente ao próprio estado e outras regiões do país, os municípios paulistas, excluída a RMSP, ampliavam sua participação no produto industrial estadual, passando de $25 \%$ para $40 \%$ entre 1970 e 1990, o que significou um salto de $14 \%$ para $20 \%$ no produto industrial do país.

Dessa maneira, o processo de desconcentração espacial da indústria no Brasil pode ser dividido em dois períodos, como sugerido por Cano (2007). O primeiro é o da desconcentração virtuosa, ocorrida na década de 1970 e marcada por uma perda relativa da participação de São Paulo no produto industrial, tendo as demais regiões do país, com as exceções anteriormente citadas, apresentado maior crescimento em suas participações relativas em virtude do maior adensamento das cadeias produtivas nacionais, que passaram a se integrar regionalmente de maneira vigorosa.

Dessa forma, todas as regiões apresentaram crescimento excepcional em termos absolutos. O segundo movimento é o da desconcentração espúria, ocorrido a partir dos anos 1980 e que remete aos constrangimentos oriundos da crise da dívida, do esgotamento do modelo de substituição de importações, da reorientação restritiva do papel do Estado enquanto planejador e coordenador dos investimentos e, por fim, da reestruturação produtiva empreendida pelas empresas transnacionais em meio à $3^{a}$ Revolução Industrial. Esta última remodelou a divisão internacional do trabalho em termos setoriais e espaciais, tanto ao deslocar parte do emprego industrial para o setor de serviços quanto pela abertura de novas unidades produtivas em regiões sem experiência industrial até os anos 1980, notadamente no Leste Europeu e na Ásia.

Soma-se a esse conjunto de fatores a abrupta e acelerada abertura financeira e comercial dos anos 1990, na esteira das recomendações do chamado "Consenso de Washington". O Plano Real teve importante papel nesse processo ao promover, como política debeladora da inflação, uma ampla indexação de preços e a "ancoragem cambial" - induzindo uma forte apreciação da moeda nacional 
em relação ao dólar norte-americano -, o que, num contexto de política monetária contracionista, liberalização dos fluxos financeiros e maior abertura ao mercado externo, terminou por promover uma concorrência desigual entre os bens manufaturados domésticos e estrangeiros.

Esse movimento contribuiu para debilitar sobremaneira o parque industrial nacional sobretudo o paulista - em benefício das importações, desconsertando notadamente os setores de bens intermediários e de capital, mas também os de consumo corrente. Desmantelavam-se progressivamente, assim, os elos regionais da indústria. As regiões que minimizavam suas perdas ou mantinham-se estagnadas "ganhavam" posição em termos relativos, num cenário de deterioração generalizada para o setor, resultando em "ilusões estatísticas" acerca das dinâmicas regionais.

O rebaixamento das políticas públicas regionais na agenda do executivo federal, bem exemplificado pela extinção das superintendências de desenvolvimento regional ${ }^{3}$, legou aos entes subnacionais uma corrida fratricida pela integração às cadeias globais de valor e à atração do investimento privado em seus territórios via incentivos fiscais, processo conhecido como "guerra fiscal". Sem dispor de instrumentos adequados para fazer frente a um movimento que tendia à reconcentração espacial da produção nas regiões de maior base econômica e infraestrutura consolidada, fundamentalmente localizadas nos centros urbanos do Sudeste e Sul do país, a "guerra fiscal" induziu (e ainda induz) a distorções de consequências deletérias à saúde fiscal de estados e municípios. Esse quadro é agravado pela desindustrialização precoce que penaliza, direta e indiretamente, a todos, na medida em que a indústria tem grande peso na arrecadação tributária e expressivos efeitos multiplicadores no emprego e na renda, atributos atenuados ou mesmo anulados tanto pela precipitada política de incentivos dos entes subnacionais quanto pela fragilização estrutural do setor manufatureiro. Esses efeitos adversos rebatem de forma perniciosa nas regiões de menor dinamismo, que tem suas possibilidades de alguma diversificação produtiva e melhoria da renda via indústria abortadas.

Concomitantemente a esse conjunto de elementos, que só poderia corroborar a atrofia do setor manufatureiro e das dinâmicas regionais nele apoiadas, o modelo de inserção externa adotado desde o final do século passado se orientou pelo reforço às vantagens comparativas em bens primários, em parte consentindo à própria incapacidade de reação da indústria nacional, ampliando assim a vulnerabilidade do país a choques externos, visto as características do mercado global para esses produtos (Carneiro, 2012). Dessa maneira, o Brasil se inseriu de forma passiva e subordinada à nova dinâmica mundial dos anos 1990, referida como "globalização".

\section{Regiões à deriva: as políticas de desenvolvimento regional no século XXI}

Um esforço para reinserir a pauta do desenvolvimento regional nas atenções do executivo federal foi empenhado com a Política Nacional de Desenvolvimento Regional (PNDR), formulada a partir de 2003 e instituída por decreto-lei presidencial em 2007. O próprio intervalo entre formulação e aprovação legal da PNDR sinaliza as dificuldades em se articular um projeto de desenvolvimento

(3) A Superintendência do Desenvolvimento da Amazônia (Sudam) e a Superintendência do Desenvolvimento do Nordeste (Sudene) foram fechadas no segundo mandato de Fernando Henrique Cardoso, em 2001; a Superintendência do Desenvolvimento do Centro-Oeste (Sudeco) foi extinta no governo der Fernando Collor, em 1990. Em seus lugares, figuraram agências de desenvolvimento com recursos e objetivos desidratados. 
regionalmente estruturado num contexto em que os investimentos públicos estratégicos e as condições para a indução do investimento privado foram solapados por políticas econômicas de corte conservador. Soma-se a isso a deterioração das condições técnicas e de planejamento do setor público após décadas de contínua reorientação do papel do Estado que, se durante os anos 1980 e parte dos 1990 estava empenhado em conter a sangria das contas públicas e o processo hiperinflacionário, este passou a se pautar de maneira mais intensa, a partir de meados dos anos 1990, pela alienação de ativos e de poder decisório em diversas frentes, supostamente a fim de favorecer uma alocação mais eficiente de recursos liderada pelo setor privado com as privatizações e, ao mesmo tempo, garantir com estas os influxos de dólares para a manutenção da âncora cambial (Filgueiras, 2000).

Apesar dos avanços em termos de tipologia e de entendimento socioeconômico do território (Macedo; Porto, 2018; 2020), a PNDR não atingiu os objetivos almejados, passando por uma reformulação que resultou em sua atualização pelo Decreto n. 9.810, de 2019. Ainda que signifique um avanço em termos de intencionalidade da política pública, sua execução é de difícil realização devido ao contingenciamento dos recursos e, de maneira mais ampla, aos entraves macroeconômicos para o desenvolvimento. A problematização destes entraves transparece nas escolhas temáticas que Wilson Cano recorrentemente fez ao longo das duas décadas deste século, apontando que a superação dos problemas de dimensão regional está visceralmente subordinada à superação dos obstáculos ao desenvolvimento, das transformações nas estruturas produtivas e das escolhas políticas referidas no longo prazo. Seu último artigo publicado em vida, "Brasil - Construção e desconstrução do desenvolvimento" (2017), versa sobre as dificuldades impostas pela longa crise iniciada nos anos 1980, demonstrando seu profundo desgosto com as armadilhas que a condição de país periférico circunstancialmente faz crer conjunturais, mas que no fundo remetem à interdição dos caminhos para a construção de um projeto de desenvolvimento nacional, entendido enquanto crescimento econômico com justiça social.

Articulando uma leitura do contexto econômico nacional e sua integração externa com as dinâmicas territoriais do país, Brandão (2019) sugeriu uma caracterização dos investimentos por região e construiu uma tipologia que as qualifica em cinco, sendo elas predominantemente impactadas e (re)definidas: i) pela demanda global de commodities; ii) pelos investimentos realizados ou orientados pelo Estado nas infraestruturas econômicas; iii) pela força inercial dos fatores de aglomeração e urbanização e as externalidades positivas daí resultantes; $i v$ ) investimentos pontuais restritos à atividade de interesse, que tendem a formar enclaves ou polos de baixíssimos encadeamentos no entorno; e v) melhora no nível de renda por conta de políticas sociais distributivas, alargando os mercados locais.

Essa leitura aponta para impactos regionais diferenciados resultantes de políticas regionais implícitas e explícitas. As políticas compensatórias e de valorização do salário-mínimo ativaram efeitos econômicos regionais importantes, sendo uma externalidade positiva destas, e não um objetivo específico da política de corte territorial. Por isso são políticas regionais "implícitas". Já a decisão microeconômica pelo investimento em determinada região pode ser franqueada por dispositivos tradicionais ("explícitos") de atração de capitais, como isenções tributárias e subsídios creditícios, à exemplo do praticado tradicionalmente pelas superintendências e bancos de desenvolvimento regionais, mas não necessariamente são resultantes desses estímulos. Portanto, a definição do "implícito" e "explícito" não é clara em todas as circunstâncias, mas é razoável supor que os 
investimentos relevantes no território sejam captados, ou de alguma forma caracterizados, por ao menos uma das classificações propostas por essa tipologia.

É o caso da expansão da fronteira agropecuária brasileira nas regiões Centro-Oeste, Norte e Nordeste do país, que responde aos estímulos externos da demanda por commodities. Tendo em vista a volatilidade característica desse mercado e a vulnerabilidade na qual as regiões produtoras se veem quando especializadas nestas atividades, a elaboração de políticas que apontem alternativas de produção e integração econômica com o restante do território parecem relevantes (Severian, 2021). Ademais, a força da representatividade dos interesses ligados ao setor primário-exportador centraliza boa parte das intervenções do poder público no território na forma das infraestruturas econômicas, principalmente as relativas à logística, que procuram integrar as zonas de produção às regiões litorâneas para a exportação, reduzindo-se assim os custos do setor. Dessa maneira, há pelo menos a forte integração entre três tipologias apontadas por Brandão: os investimentos ligados às commodities tendem a criar certos investimentos com característica de enclave no território, ao mesmo tempo que aciona os investimentos públicos no sentido de suportar as atividades ligadas ao impulso externo. Por óbvio, as intervenções no território nesses casos não derivam do planejamento regional enquanto política de integração nacional e elevação da renda, ainda que estas invariavelmente acessem o fundo público para realizarem-se, mas sim de demandas de um segmento privado que acaba definindo o ordenamento territorial segundo seus interesses particulares. Portanto, não se trata de uma mitigação dos "desequilíbrios regionais" históricos ou de uma intervenção lastreada num projeto de desenvolvimento nacional, mas sim da viabilização e ampliação do excedente acumulado por um setor de ascendente - e talvez dominante - importância na fluência política e econômica do país.

Todavia não se pode desconsiderar os impactos positivos que a infraestrutura logística possibilita às regiões por ela conectada, mesmo que sua fundamentação seja voltada a interesses específicos, dado que estas permitem a integração inter e intrarregional e a viabilização de negócios em sua extensão. Contudo, é importante destacar que o vigor dessas externalidades na escala regional é amplamente dependente das condições gerais do crescimento econômico e do padrão de distribuição da renda, e não só das dinâmicas do mercado externo que animam as atividades ligadas ao setor primário. Em suma, os estímulos do ambiente econômico como um todo são responsáveis pelo maior ou menor sucesso das políticas regionais "implícitas" ou "explícitas".

Se a tipologia sugerida por Brandão permite qualificar certas intervenções e transformações no território, ela não parece suficientemente calibrada para apontar áreas preferenciais de atuação da política regional, uma vez que não oferece uma compreensão das singularidades do território, deixando descobertas aquelas regiões que não são alvo da expansão agropecuária, nem das políticas regionais explícitas e nem polos atrativos à localização empresarial por conta de uma eventual expansão da renda derivada dos programas de transferência. Por sua vez, Macedo e Porto (2018; 2020) sugeriram uma tipologia que considera indicadores demográficos, de produção e renda para a qualificação de regiões, em escala microrregional, elegíveis à atuação da política pública dentro do escopo da PNDR. Através da combinação de variáveis selecionadas e previstas pela própria política, os autores chegaram a quatro classificações territoriais possíveis: $i$ ) sub-regiões de alta renda, que congregam o quartil de microrregiões com maior rendimento por habitante do país; ii) sub-regiões de baixa renda, que agrupam o quartil inferior das microrregiões, com menor renda nominal por habitante e menor crescimento per capita do PIB; iii) sub-regiões dinâmicas, obtidas pelo cruzamento 
das informações do rendimento médio com o PIB per capita; agregando microrregiões com maiores taxas de crescimento do PIB per capita, mas que não figuram no grupo de alta renda; $i v$ ) sub-regiões estagnadas, sendo aquelas que apresentam valores intermediários de rendimento médio por habitante, mas com taxas médias ou baixas de crescimento do PIB per capita.

Por fim vale destacar que a recente profusão de políticas públicas com "explícita" orientação regional tem apresentado baixa efetividade, sendo ora redundantes, se sobrepondo umas às outras, ora carecendo de foco e objetivos realistas alcançáveis no horizonte programado, com todas sofrendo conjuntamente com a escassez de recursos e visão de conjunto, conformando uma estratégia de desenvolvimento nacional assentada em bases regionais ${ }^{4}$. Posto de outra forma, a falta de coordenação na elaboração e execução das políticas que elencam as várias dimensões do desenvolvimento, e não apenas as de viés territorial, terminam fragilizadas pelo desprestígio ao planejamento estatal, frustrando os primados indicadores de eficácia, eficiência e efetividade do setor público.

Descasada dos instrumentos de coordenação com uma clara orientação ao desenvolvimento nacional, as políticas de corte regional tendem a se reduzir a ações circunstanciais e frágeis de "inclusão produtiva", tão ao gosto de certas organizações da sociedade civil, de atuação tipicamente atomizadas, que buscam preencher lacunas sociais desassistidas pelo Estado. Esse perfil de intervenção desnatura o sentido de abrangência, perenidade e transformação das estruturas regionais, algo esperado nas políticas públicas com esse viés. Ou seja, as políticas regionais muitas vezes podem estar fadadas a se limitarem à remediação ou atendimento pontual das carências materiais espacialmente delimitadas por meio da promoção do trabalho digno, que abrange a família ou a comunidade, mas que replicam estruturas autárquicas ou semi-autárquicas de provimento material da vida, como no caso da criação e agricultura de subsistência.

\section{$4 \mathrm{O}$ desmonte do desenvolvimento: descaminhos do neoliberalismo e o ponto em que estamos}

A crise no setor industrial brasileiro é estrutural e persiste há anos. Vários fatores estruturais têm impactado negativamente a indústria brasileira, que vive os efeitos da desindustrialização precoce. Como destaca Wilson Cano em várias das suas obras, a desindustrialização brasileira decorre de quatro principais fatores:

1) a política cambial vigente a partir do Plano Real (1994). Longos períodos de valorização da moeda brasileira, se por um lado serviram de "âncora dos preços", por outro, prejudicaram a competitividade da produção e da exportação dos produtos industriais brasileiros; 2) A abertura comercial desde 1989, ainda no governo Sarney, quando se iniciou um processo de desmonte da proteção existente para a indústria brasileira, que foi ampliada no governo Collor, em 1990 e intensificada no governo de Fernando Henrique Cardoso, a partir de 1994, a qual prevalece até os

(4) Atualmente o Ministério do Desenvolvimento Regional (MDR) administra onze políticas nacionais voltadas ao tema: Além da Política Nacional de Desenvolvimento Regional, há a Política Nacional de Desenvolvimento Urbano, Política Nacional de Proteção e Defesa Civil, Política Nacional de Recursos Hídricos, Política Nacional de Segurança Hídrica, Política Nacional de Irrigação (compartilhada com o Ministério da Agricultura, Pecuária e Abastecimento), Política Nacional de Habitação, Política Nacional de Saneamento, Política Nacional de Mobilidade Urbana, Política de subsídio à habitação popular, saneamento e mobilidade urbana, e Política Nacional de Ordenamento Territorial. 
dias de hoje; 3) as taxas de juros reais elevadas, que tanto leva ao "rentismo" dos agentes como inviabiliza o crédito e o financiamento para a produção; 4) o investimento direto estrangeiro. Embora tenham sido relevantes os influxos desses capitais ao longo das últimas décadas, eles pouco contribuíram efetivamente para elevação da Formação Bruta de Capital Fixo, uma vez que concentrados em fusões e aquisições de empresas já existentes e de baixa inserção no mercado internacional. 5) o quadro internacional mais complexo com o acirramento da competitividade entre EUA, Europa e China, tornando ainda mais difícil o desafio brasileiro (Cano, 2012).

Da mesma forma, essas condições macroeconômicas desfavoráveis e a ausência ou insuficiência de políticas de competitividade (industrial, comercial e de inovação) tampouco tiveram ações sistemáticas, exceto algumas tentativas nos governos Lula e Dilma, para tentar reverter esse quadro.

Desde o início dos anos 1990, as alíquotas médias de importação caíram de mais de 40\%, no final dos anos oitenta do século passado, para cerca de 11 a $12 \%$ vigentes atualmente, com algumas alternâncias. A questão, no entanto, é que os fatores de competitividade sistêmica, todos aqueles que independem das empresas em si, ou dos trabalhadores, mas que afetam a competitividade, não avançaram na mesma velocidade da abertura havida.

O resultado foi o avanço das importações, especialmente advindas da China, substituindo a produção local. As exportações de bens industrializados também foram prejudicadas pelos mesmos fatores mencionados e perderam espaço, ou estagnaram em um mercado internacional hipercompetitivo. A balança comercial brasileira tem sido superavitária ao longo das últimas duas décadas, influenciada pelo excelente desempenho dos complexos agropecuário-minerais, como grãos, petróleo bruto e carnes. Mas a questão aqui não é "ou", mas, "e". O Brasil é um dos poucos países que poderia manter ampla pauta de produção e exportação nos setores em que já mantem posição de destaque sem que, no entanto, isso viesse a ocorrer em detrimento da indústria e serviços sofisticados.

Os industriais brasileiros, aqueles que não atuaram em setores diretamente ligados a commodities, ou de setores oligopolizados, acabaram sucumbindo, até mesmo por sobrevivência, ou senso de oportunidade, para a importação e o rentismo. Mais recentemente, depois da crise de 2015/2016 e nos anos seguintes, a crise brasileira tem impactado significativamente a indústria brasileira.

O discurso neoliberal de que a indústria não investe em modernização e inovação cai no erro de não identificar a raiz do problema, que não se restringe à ação microeconômica das empresas, mas a um ambiente sistêmico desfavorável. O investimento, de forma geral, responde à rentabilidade esperada, que no caso é prejudicada pelas condições adversas do ambiente econômico. Infelizmente, a combinação de fatores adversos nos levou a uma desindustrialização precoce, levando à perda na capacidade de geração de valor agregado, de empregos de qualidade e de tecnologia atualizada.

Um programa concreto de desenvolvimento passa necessariamente pela construção de condições macroeconômicas que favoreçam a reindustrialização, algo que não está presente nas escolhas das políticas econômicas vigentes no País. Partindo-se do ajuste das condições sistêmicas, seria possível rever a estrutura das alíquotas, porém, sem generalizações. Seria preciso começar a intensificação com a desoneração dos insumos de forma a dotar a indústria de transformação de maior 
poder, ao contrário de estimular a concorrência via rebaixamento das tarifas de importação dos produtos finais. Não se trata de "reinventar a roda", mas de adotar práticas internacionais bemsucedidas. Isso pressuporia, contudo, uma autonomia inexistente na correlação de forças dominantes na definição das políticas econômicas.

A pandemia do novo Coronavírus (Covid-19), além de imenso flagelo humano e social para o mundo, também traz consequências gravíssimas para a economia global ao provocar uma recessão. O impacto para a atividade econômica no Brasil implicou uma contração superior a $4 \%$ do PIB em 2020. No entanto, alguns aspectos devem ser considerados: o primeiro é que bem antes da situação recente, a economia brasileira já vinha apresentando um quadro continuado de estagnação. No acumulado 2017-2019 o PIB per capita não cresceu mais do que apenas 0,3\% ao ano, depois da queda de 6\% acumulada em 2015-2016. Os investimentos, medidos pela Formação Bruta de Capital Fixo, estavam em 2020 em um nível cerca de 25\% inferior a 2014.

O aumento da nossa dependência de produção e exportação de commodities, ou de produtos de baixa complexidade e valor agregado, nos afeta de forma expressiva na atual crise. Além disso, também nos tornamos dependentes de partes e componentes produzidos em regiões da China que tem sido fortemente afetadas, prejudicando a produção brasileira. O aumento da incerteza exacerba a volatilidade dos mercados, com impactos nos juros, câmbio e bolsas. Esses efeitos combinados têm provocado postergação, ou mesmo cancelamento, de novos projetos, investimentos e contratações, aprofundando a contração da atividade.

Diante desse quadro, a adoção de um conjunto de políticas e medidas anticíclicas por parte do Estado se mostram imprescindíveis. Para o Brasil, especialmente, dada a nossa extrema desigualdade regional e de renda, além da elevada vulnerabilidade de milhões de brasileiros, essas medidas se tornaram ainda mais cruciais. Mas, ressalte-se, a questão fundamental, como destaca Cano, está na ausência de um projeto nacional de desenvolvimento, sem o qual o Brasil se mantém refém das medidas paliativas ao sabor da conjuntura, sem alterar o seu quadro grave de desindustrialização e todas as consequências no que se refere à vulnerabilidade externa, precarização do emprego e da renda e ausência de condições autônomas de superação da crise.

\section{Conclusão}

O percurso realizado de revisitar aspectos relevantes da obra de Wilson Cano joga luz para o debate dos grandes desafios atuais da retomada do desenvolvimento brasileiro. A análise dos descaminhos percorridos pela economia brasileira também nos revela a importância e necessidade de mudanças. A orientação do desenvolvimento econômico assentado na integração regional é urgente para dar cabo às profundas desigualdades socioeconômicas do país.

Apesar de certa variedade no número de políticas públicas voltadas ao território, a efetividade destas está combalida pela falta de coordenação e integração das ações, reflexo da carência de uma estratégia de desenvolvimento do país que articule as regiões no sentido do crescimento, com preservação ambiental e justiça distributiva. Para isso, o refortalecimento da manufatura, com associação aos serviços digitais sofisticados, é fundamental. 
É possível reverter a desindustrialização em curso no Brasil e promover uma reindustrialização. No entanto, isso não será fácil, e nem algo automático, ou natural. Terá que ser um processo induzido, mediante a criação de um ambiente macroeconômico mais favorável à produção, à adoção de políticas de competitividade (ou seja, políticas industrial, comercial e de inovação), além do fomento à inovação e cultura empresarial com o intercâmbio universidade institutos de pesquisa - empresas.

É importante ressaltar que a tarefa de se reindustrializar não ocorrerá apenas com a ação do mercado. Também, e fundamentalmente, esta depende de um projeto bem articulado, com participação e coordenação do Estado. O Brasil, para isso, conta com algumas vantagens: detém economias de escala e de escopo, possui um mercado consumidor dos maiores do mundo, o que pode viabilizar muitas atividades internamente. Da mesma forma, apesar da desindustrialização precoce em curso, ainda detém o maior parque industrial da América Latina.

Mas, se nosso país é detentor de tamanha potencialidade, por outro lado há aspectos limitadores: a política econômica de cunho liberal, a ausência de um pensamento econômico da produção por parte das entidades representativas da indústria, e o "pensamento único" vigente no (falso) debate econômico que chega ao grande público basicamente por via dos grandes meios de comunicação.

A política econômica em vigor no Brasil, além de limitada, ultrapassada e restrita, causa estragos. Um deles, nessa gestão Bolsonaro/Guedes de visão simplificadora e sob o argumento da "racionalização", promoveu, logo no seu início (2019), a junção de vários antigos ministérios em um único, o da Economia. Os ex-ministérios da Fazenda, do Planejamento, da Indústria e Comércio Exterior, do Emprego e Trabalho, que já havia incorporado a Previdência em 2017, no governo Temer, estão agora integrados numa mesma estrutura. Mas, muito ao contrário do prometido, a junção tirou da agenda todos os aspectos envolvidos na questão da indústria. Não há interlocutores qualificados e empoderados para dialogar com o setor produtivo. Este, envolvido pelo pensamento dominante, também, com raras exceções, não consegue apresentar e defender uma agenda alternativa. Prevalece o desgastado discurso inócuo das tais "reformas", nem sempre transparentes, e a visão equivocada do "ajuste fiscal", do "Estado mínimo" e outras.

A propalada ênfase no "ajuste fiscal", além de reducionista, pretende resgatar a chamada "confiança", o que daria respaldo à retomada do crescimento. Como já anotou com propriedade Paul Krugman, Prêmio Nobel de Economia, seria o mesmo que acreditar nos poderes da "fada da confiança". "Desenvolvimento é ser dono do próprio destino", pontificava o mestre Celso Furtado, inspirador de Wilson Cano. Sem um claro projeto de Nação, permaneceremos reféns do subdesenvolvimento e distantes da Nação que poderíamos ser. Wilson Cano e sua obra nos dá relevantes pistas do que realmente importa na questão do desenvolvimento brasileiro!

\section{Bibliografia}

BRANDÃO, Carlos A. As ausências e os elos faltantes nas análises regionais no Brasil e a proposição de uma agenda de pesquisa de longo prazo. Rio de Janeiro: Ipea, mar. 2019. (Texto para Discussão, n. 2461). 
Danilo Severian, Antonio Corrêa de Lacerda

CANO, Wilson (Coord.). O processo de interiorização da indústria paulista - 1920 a 1980. São Paulo: Fundação SEADE, 1988. (Coleção Economia Paulista).

CANO, Wilson. Raízes da concentração industrial em São Paulo. 3. ed. São Paulo: Hucitec, 1991 [1977].

CANO, Wilson. Auge e inflexão da desconcentração econômica regional. In: AFFONSO, R. B. A.; SILVA, P. B. (Org.). A Federação em perspectiva. São Paulo: Fundap, 1995, p. 319-415.

CANO, Wilson. A desconcentração espacial da indústria paulista. Boletim Regional - Informativo da Política Nacional de Desenvolvimento Regional, Brasília, n. 1, p. 18-22, 2006.

CANO, Wilson. Desequilíbrios regionais e concentração industrial no Brasil - 1930-1970. São Paulo: Editora Unesp: 2007 [1981].

CANO, Wilson. Desconcentração produtiva e regional no Brasil: 1970-2005. São Paulo: Editora Unesp, 2008.

CANO, Wilson. Reflexões sobre o papel do capital mercantil na questão regional e urbana do Brasil. Revista da Sociedade Brasileira de Economia Política, São Paulo, n. 27, p. 29-57, out. 2010.

CANO, Wilson. Novas determinações sobre as questões regional e urbana após 1980. Revista Brasileira de Estudos Regionais e Urbanos, v. 13, n. 2, p. 27-55, nov. 2011.

CANO, Wilson. A desindustrialização no Brasil. Economia e Sociedade, Campinas, v. 21, Número Especial, p. 831-851, dez. 2012.

CANO, Wilson. Brasil - Construção e desconstrução do desenvolvimento. Economia e Sociedade, Campinas, v. 26, n. 2 (60), p. 263-302, ago. 2017.

CARNEIRO, Ricardo. Commodities, choques externos e crescimento: reflexões sobre a América Latina. Santiago do Chile: Cepal, jan. 2012.

DINIZ, Clélio Campolina. Dinâmica regional da indústria no Brasil: início de desconcentração, risco de reconcentração. Tese (Professor Titular)-Belo Horizonte, UFMG, 1991.

DINIZ, Clélio Campolina. Desenvolvimento poligonal no Brasil: nem desconcentração, nem contínua polarização. Nova Economia, [s. 1.], v. 3, n. 1, 1993.

DINIZ, Clélio Campolina. A dinâmica regional recente da economia brasileira e suas perspectivas. Rio de Janeiro: Ipea, jun. 1995. (Texto para Discussão, n. 375).

FILGUEIRAS, Luiz. História do Plano Real. São Paulo: Boitempo Editorial, 2000.

GTDN. Grupo de Trabalho para o Desenvolvimento do Nordeste. Conselho de Desenvolvimento. Presidência da República. Uma política de desenvolvimento econômico para o Nordeste. Rio de Janeiro: Departamento de Imprensa Nacional, 1959.

HIRSCHMAN, Albert O. Estratégia do desenvolvimento econômico. Rio de Janeiro: Editora Fundo de Cultura, 1961.

MACEDO, Fernando C. de; PORTO, Leonardo R. Proposta de atualização das tipologias da PNDR: Nnota metodológica e mapas de referência. Brasília: Ipea, set. 2018. (Texto para Discussão, n. 2414). 
MELLO, João Manuel Cardoso de. O capitalismo tardio. 8. ed. São Paulo: Ed. Brasiliense, 1991.

MYRDAL, Gunnar. Teoria econômica e regiões subdesenvolvidas. Rio de Janeiro: Editora Saga, 1965.

PERROUX, François. A economia do século XX. Lisboa: Editora Herder, 1967.

SEVERIAN, Danilo. Regiões especializadas em commodities: apontamentos sobre a estrutura fiscal e produtiva em contexto de regressão estrutural da economia brasileira. Boletim Regional, Urbano e Ambiental, Brasília, Ipea, n. 21, jan./jun. 2021.

SEVERIAN, Danilo. Indústria e Território no Brasil: desenvolvimento regional e divisão interna do trabalho industrial no Brasil entre 1995 e 2015. Dissertação (Mestrado em Economia)-Programa de Estudos Pós-Graduados em Economia Política, Pontífice Universidade Católica, SP, 2019.

TAVARES, M. C. O processo de substituição de importações como modelo de desenvolvimento na América Latina. In: BIELSCHOWNSKY, R. Cinquenta anos de pensamento na Cepal. Rio de Janeiro: Editora Record, 2000. 